\section{A lei n. 12.551/2011 e seus reflexos no teletrabalho docente na educação a distância.}

Sergio Timo Alves *

\section{Resumo}

Este artigo busca estabelecer os possíveis reflexos da Lei n. 12.551/2011 no teletrabalho ${ }^{1}$ do docente da educação a distância. Inicialmente, faz-se a exposição do momento anterior, e posterior, à referida Lei. Passa-se, então, aos contornos legais do teletrabalho docente nos termos da Lei de Diretrizes e Bases (Lei n. 9.394/1996) e da Consolidação das Leis do Trabalho (CLT), alterada pela Lei n. 12.551/2011. O objetivo é fixar o alcance da alteração normativa e responder à seguinte pergunta: em que medida ela poderá impactar na profissão docente na educação a distância? A partir da análise empreendida, conclui-se que a referida legislação explicita e regula uma situação já existente, mas não a altera em essência, devendo ser preferida a via interpretativa que proteja os teletrabalhadores docentes, mas que, ao mesmo tempo, não impeça, se é que isso seja possível, o caminhar do teletrabalho em geral e do teletrabalho docente em específico, por ser um fenômeno irreversível do próprio do desenvolvimento tecnológico do estágio atual da pós-modernidade.

Palavras-chave: Teletrabalho; Lei 12.551/2011; Docência na educação a distância.

\section{Introdução}

O incremento das tecnologias da informação e comunicação (TICs) aplicadas aos mais diversos setores da vida social fez antever uma nova revolução para além da burguesa, da industrial ou da socialista, isto é, a revolução tecnológica que, assim como as demais, tem aptidão para alterar profundamente a relação capital/trabalho. Em decorrência das mudanças nessa relação, nesta era informacional, já se podia esperar também pela mudança legislativa ocorrida no Brasil, com o advento da Lei 12.551 , de 16 de dezembro de 2011, que pretende adaptar a legislação trabalhista contida na Consolidação das Leis do Trabalho (CLT) aos novos tempos.

Noutra vertente, é perceptível que o avanço tecnológico tem refletido fortemente na docência, seja na educação a distância (EAD), seja no uso das tecnologias como ferramentas complementares na educação tradicional presencial.

Especificamente, na educação à distância a relativização do
* Possui graduação em Direito pela PUC Minas (1998), especialização em Direito Processual (2000) e mestrado em Direito Público pela PUC Minas (2004). Atualmente, é professor assistente IV da PUC Minas e Procurador do Estado de Minas Gerais. Tem experiência na área de Direito, com ênfase em Direito Administrativo e Tributário.

1 Preferiu-se teletrabalho, termo que ve sendo adotado na literatura jurídica especializada, a home office, também para priorizar o uso do vernáculo.

Revista @rquivo Brasileiro de Educação, Belo Horizonte, vol.2, num.3, jan-jun, 2014. 
tempo e do espaço e o acesso às mais longínquas localidades aparecem como diferenciais de destaque. No entanto, questionamentos sobre a segmentação da atividade docente e sua precarização com aumento de atribuições, além do impacto das tecnologias no trabalho do professor, também se fazem presentes. $O$ teletrabalho docente é um campo novo de estudo. Carece-se, até o momento, de uma disciplina específica da relação de emprego do teletrabalhador docente, em especial no que toca aos seus direitos trabalhistas.

A Lei n. 12.551/2011, ao dar nova redação ao art. $6^{\circ}$ da CLT, equiparou os efeitos jurídicos da subordinação jurídica exercida a distância, por meios telemáticos e informatizados, à subordinação exercida por meios pessoais e diretos de comando, controle e supervisão do trabalho alheio. A referida lei teve por intento adaptar a ordem jurídica às transformações do mundo do trabalho que advieram da revolução tecnológica, conforme consta na justificativa do Projeto de Lei n. 3.129, de 2004, que deu origem a Lei 12.551/2011.

Ainda que não destinada especificamente ao trabalho docente na educação a distância, a aludida lei se aplica ao docente que atua nessa modalidade. Ocorre que a equiparação do trabalho sob a supervisão direta do empregador àquele mediado por aparatos telemáticos parece não resolver todas as questões até então postas, mesmo porque não se atentou para os problemas específicos dessa nova forma de se prestar o trabalho.

O presente artigo objetiva, pois, responder à indagação sobre os possíveis reflexos que a Lei n. 12.551/2011 acarretará no teletrabalho docente na educação a distância. Para uma abordagem contextualizada da questão envolta nessa lei deve-se atentar, ainda que em rápidas pinceladas, para a evolução das formas de Estado.

No Estado liberal, acreditava-se no dogma da autorregulação do mercado, cabendo ao Poder Público apenas e tão somente garantir meios de segurança para que as forças econômicas da livre iniciativa e livre concorrência pudessem atuar. Nessa quadra histórica, surgem normas que visam a impedir o Estado de intervir na liberdade individual por meio de abstenções e com a declaração formal de liberdades individuais.

O passo seguinte, no segmento social prevaleceu a idéia de que cumpre ao Estado uma atuação positiva, nos campos econômico e social, capaz de efetivar o princípio da igualdade. Já não mais se contenta com uma atuação negativa do Estado. Antes, exige-se a crescente atuação

Revista @rquivo Brasileiro de Educação, Belo Horizonte, vol.2, num.3, jan-jun, 2014. 
deste no oferecimento de serviços públicos e na ingerência perante a ordem econômica e social, aptos a regular e conter o mercado, protegendo os cidadãos. Despontam, dessa forma, os direitos sociais de caráter individual e coletivo. Por essa ocasião, ganha força o Direito do Trabalho, como ramo do Direito no qual se regulam as relações de trabalho em vista da compatibilização do lucro da empresa com a dignidade do trabalhador.

Superados o Estado liberal, operador de graves distorções, e o Estado social, intervencionista e gerador de passivos financeiros ao erário, surge o Estado neoliberal, que aparece, em tese, como mediador que regula e corrige as distorções do mercado abstendo-se, em princípio, de uma atuação direta na economia. Aplica-se a teoria da subsidiariedade. No âmbito trabalhista, prega-se não mais um retorno ao livre jogo das forças envolvidas na relação capital e trabalho, mas uma "flexibilização" trabalhista, que mesmo apregoada e decantada, ainda não encontrou eco na legislação brasileira.

Pois bem. $\mathrm{O}$ art. $6^{\circ}$ da CLT, que é de 1943 , contava com a seguinte redação:

Art. $6^{\circ}$. Não se distingue entre o trabalho realizado no estabelecimento do empregador e o executado no domićlio do empregado, desde que esteja caracterizada a relação de emprego.

No contexto acima referido, a Lei $12.551 / 2011$ passou a prescrever:

Art. $6^{\circ}$. Não se distingue entre o trabalho realizado no estabelecimento do empregador, o executado no domicílio do empregado e o realizado a distância, desde que estejam caracterizados os pressupostos da relação de emprego.

Parágrafo único. Os meios telemáticos e informatizados de comando, controle e supervisão se equiparam, para fins de subordinação jurídica, aos meios pessoais e diretos de comando, controle e supervisão do trabalho alheio.

A nova Lei, aplicável a todo trabalhador regido pela $\mathrm{CLT}^{2}$, foi editada pela União com suporte na sua competência legislativa centes ocupantes de cargos públicos de provimento efetivo em alguma das unidades da federação, regidos por estatuto legal próprio (estatutários) e privativa para preceituar sobre Direito do Trabalho, prevista no art. 22, I, da Constituição Federal. De certo que, exercida tal competência, com olhos postos no art. 70, inciso XXVII, da mesma Carta, prevê "a proteção em face à automação, na forma da lei" e nas diretrizes oriundas da

Revista @rquivo Brasileiro de Educação, Belo Horizonte, vol.2, num.3, jan-jun, 2014. 
Convenção n. 177, de 1996, da Organização Internacional do Trabalho $\left(\mathrm{OIT}^{3}\right)$. Especificamente, quanto aos profissionais da educação, impõe a Constituição que os mesmos sejam "valorizados", nos termos do art. 206, V, o que deve influir na interpretação do art. $6^{\circ}$ da CLT quanto ao profissional docente.

O teletrabalho é uma questão trabalhista típica dos dias atuais. Nascimento observa que:

Não há conceito legal de trabalho a distância, mas a expressão é usada para designar o trabalho que não é realizado no estabelecimento do empregador, e sim fora dele, portanto, com a utilização dos meios de comunicação que o avanço das técnicas modernas põe a disposição do processo produtivo, em especial de serviços. Não há rigor conceitual porque ainda está por ser feito o estudo desses meios e a forma como na sociedade contemporânea vem sendo utilizado (NASCIMENTO, 2008, p. 1070).

O fato é que o teletrabalho não se resume ao trabalho em domicílio. Isso porque "o teletrabalho se refere às prestações de serviço fora da Empresa, utilizando-se, como contato, os meios de comunicação e informática" (CAPELARI, 2009, p. 944). Ou seja, o trabalho a distância (aquele não realizado no estabelecimento do empregador), é um gênero que comporta como uma de suas espécies o teletrabalho, em que a distância é supostamente neutralizada pela utilização de recursos eletrônicos, das tecnologias da informação e da comunicação, inserido no fenômeno de descentralização dos processos de trabalho. Essa é também a posição acatada pela Convenção n. 177/1996, da OIT.

Na educação, defende-se que "o desenvolvimento da educação a distância em todo o mundo está associado à popularização e democratização do acesso às tecnologias de informação e comunicação" (MEC, Referenciais de qualidade para educação superior a distância, 2007, p. 10). E, de fato, a educação a distância tem a aptidão de incrementar esse acesso, mesmo trazendo contradições a merecer análise dos envolvidos.

A própria Lei n. 9394/1996, Lei de Diretrizes e Bases da Educação (LDB), em seu artigo 80, contém a seguinte previsão sobre a educação a distância:

Art. 80. O Poder Público incentivará o desenvolvimento e a veiculação de programas de educação a distância, em todos os níveis e modalidades de ensino ${ }^{4}$, e de educação continuada.
${ }^{3} \mathrm{O}$ Código de Trabalho de 2003, de Portugal, é apontado como uma legislação avançada na matéria de teletrabalho, ali previsto nos arts. 233/241

\footnotetext{
4 Parece interessante apontar um certo paradoxo entre a valorização e incremento da educação a distância no ensino superior e o aumento da escola básica presencial e em tempo integral, o que talvez se explique pela necessidade de trabalho dos pais, pelo fator segurança e pelos custos do empregado doméstico
} 
A lei n. 12.551/2011 e seus reflexos no teletrabalho docente na educação a distância.

$\S 1^{\circ} \mathrm{A}$ educação a distância, organizada com abertura e regime especiais, será oferecida por instituições especificamente credenciadas pela União.

$\S 2^{\circ} \mathrm{A}$ União regulamentará os requisitos para a realização de exames e registro de diplomas relativos a cursos de educação a distância.

$\S 3^{\circ}$ As normas para produção, controle e avaliação de programas de educação a distância e a autorização para sua implementação, caberão aos respectivos sistemas de ensino, podendo haver cooperação e integração entre os diferentes sistemas.

$\S 4^{\circ} \mathrm{A}$ educação a distância gozará de tratamento diferenciado, que incluirá:

I - custos de transmissão reduzidos em canais comerciais de radiodifusão sonora e de sons e imagens; educativas;

II - concessão de canais com finalidades exclusivamente

III - reserva de tempo mínimo, sem ônus para o Poder Público, pelos concessionários de canais comerciais.

\section{A LDB não cogita expressamente sobre os docentes da educação a distância, mas é certo que os mesmos deverão cumprir as funções a eles destinadas pelo art. 13:}

Art. 13 - Os docentes incumbir-se-ão de:

I - participar da elaboração da proposta pedagógica do estabelecimento do ensino;

II - elaborar e cumprir plano de trabalho, segundo a proposta pedagógica do estabelecimento de ensino;

III - zelar pela aprendizagem dos alunos;

IV - estabelecer estratégias de recuperação para os alunos de menos rendimento;

$\mathrm{V}$ - ministrar os dias letivos e horas-aula estabelecidos, além de participar integralmente dos períodos dedicados ao planejamento, à avaliação e ao desenvolvimento profissional;

VI - colaborar com as atividades de articulação da escola com as famílias e comunidade.

Vê-se, portanto, que a função docente na educação a distância não difere em essência da docência presencial. No entanto, como adverte Grossi:

É importante lembrar que as características que norteiam o conceito de Teletrabalho é de que o empregado não tem contato físico com seus superiores e colegas de trabalho, entretanto, está em constante comunicação com os mesmos, valendo-se exclusivamente da tecnologia que the foi ofertada pelo empregador. (GROSSI, 2008, p. 352).

Assim, na educação a distância, às atribuições convencionais do professor se somam a outras destinadas a "encurtar a distância" e 
aproximar professores e alunos, em constante interligação tecnológica, circunstância que pode significar aumento da carga de trabalho.

Tanto isso é verdade que o próprio Ministério da Educação, destaca que "é enganoso considerar que programas a distância minimizam o trabalho e a mediação do professor. Muito pelo contrário, nos cursos superiores a distância, os professores vêem suas funções se expandirem." (REFERENCIAIS DE QUALIDADE PARA A EDUCAÇÃO SUPERIOR A DISTÂNCIA, 2007, p. 20).

Logo, consideradas as atribuições do docente ligadas a elaboração do material e realização de atividades diversas com uso das tecnologias, vislumbra-se um aumento da carga de trabalho dos professores, como realça o texto a seguir:

\begin{abstract}
Além disso, a tendência atual, sobretudo, ligada à educação a distância, vem promovendo um resgate do taylorismo, que se traduz na dicotomização entre concepção e execução. Assim, alguns poucos, concebem e elaboram os "pacotes" de trabalho e a grande maioria os executam. Neste contexto, os conceptores são valorizados e bem remunerados e os "executores", geralmente denominados tutores, são expropriados dos seus saberes se tornando "profissionais" facilmente substituíveis e, consequentemente, recebem baixos salários, não tendo cobertura trabalhista.

Acresce, ainda, que se constata uma intensificação do trabalho docente, pois, os professores se veem submetidos além de suas exaustivas jornadas de trabalho, outras novas atribuições. (OLIVEIRA, PASCHOALINO e MATIAS 2008, p. 16).
\end{abstract}

Belloni chega mesmo a falar na segmentação e "transformação do professor de uma entidade individual em uma entidade coletiva" (BELLONI, 2003, p. 81). Na prática, o docente da educação a distância se responsabiliza, em geral, por número muito elevado de alunos, o que pode acarretar a precarização da sua atividade e mesmo a desumanização da relação com os alunos, dada a possibilidade de se encarar o processo de ensino/aprendizagem como algo mecânico e superficial.

De todo modo, agora, consoante o art. $6^{\circ}$ da CLT, na redação da Lei n. 12.551/2011, o teletrabalho não se distingue do trabalho presencial "desde que estejam caracterizados os pressupostos da relação de emprego". E os pressupostos da relação de emprego aludidos na norma são: a pessoalidade, a não eventualidade, a subordinação e o pagamento de salário, segundo os arts. $2^{\circ}$ e $3^{\circ}$ da CLT.

Revista @rquivo Brasileiro de Educação, Belo Horizonte, vol.2, num.3, jan-jun, 2014. 
A lei n. 12.551/2011 e seus reflexos no teletrabalho docente na educação a distância.

Há que se considerar que, mesmo antes da alteração legislativa, as relações de teletrabalho não ficavam totalmente desamparadas, mesmo porque, no Direito do Trabalho tem plena aceitação o princípio da realidade (o que vale são os fatos, ainda que rotulados de maneira diversa do que ocorrem na realidade). Especificamente no que diz respeito ao teletrabalhador docente, o Tribunal Regional do Trabalho da $3^{a}$ Região (Minas Gerais) nos autos do Recurso Ordinário TRT/004232009-042-03-00-1 RO, já decidiu, antes mesmo da Lei n.12.551/2011:

EMENTA: VÍNCULO DE EMPREGO - PROFESSOR - CURSOS A DISTÂNCIA

Como bem destaca a r. sentença recorrida, o reclamante foi contratado intuitu personae para trabalhar no assessoramento dos cursos a distância. A intermitência invocada pela reclamada não descaracteriza o vínculo jurídico de emprego entre o professor e a instituição de ensino, por não ser imprescindível que o empregado compareça ao estabelecimento de ensino todos os dias, especialmente no presente caso concreto, por ter sido contratado o reclamante para trabalhar na execução do Projeto Pedagógico dos Cursos a Distância instituído pela Universidade reclamada, portanto só comparecendo às atividades presenciais com a frequência que lhe for determinada pelo empregador, o que não descaracteriza a "não eventualidade" do vínculo jurídico contratual que preside o relacionamento jurídico entre as partes. Em se tratando de ensino à distância não é imprescindível a presença física do empregado no estabelecimento de ensino diariamente para que haja a configuração da relação de emprego, como ocorre com o trabalho externo e com o teletrabalho. Quem se insere num Projeto Pedagógico de Cursos a Distância, trabalha para o empregador em casa, participa de uma equipe de teletrabalho ou que seja contratado para trabalhar online sozinho em casa, tem plenamente preenchido o requisito da não eventualidade necessária para a proclamação judicial da existência do vínculo jurídico de emprego. Os cursos à distância até podem ter curta duração, ser sequenciados ou ser descontinuados, o que depende exclusivamente do poder de comando do empresário e não da vontade individual dos professores contratados. A atividade empresarial de educação superior adotada pela reclamada é permanente, como instituição de ensino superior privada - uma Universidade particular -, cuja característica de permanência fundamenta o princípio jurídico da continuidade da relação de emprego, de molde a afastar a suposta eventualidade por ela invocada.

Então, a inovação da lei consiste apenas em explicitar que "Os meios telemáticos e informatizados de comando, controle e supervisão se equiparam, para fins de subordinação jurídica, aos meios pessoais e diretos de comando, controle e supervisão do trabalho alheio", conforme passou a constar no parágrafo único do art. $6^{\circ}$ da CLT. O que Estrada

Revista @rquivo Brasileiro de Educação, Belo Horizonte, vol.2, num.3, jan-jun, 2014. 
(2008) prefere denominar de telessubordinação, enquanto a relação existente entre o empregador e o teletrabalhador.

Nesse sentido, a lei foi bem elaborada ao explicitar a possibilidade de haver comando, controle e supervisão, ainda que não haja o contato direto caracterizando-se a subordinação jurídica que, aliada aos demais requisitos do arts. $2^{\mathrm{a}}$ e $3^{\circ}$ da $\mathrm{CLT}$, levam à consideração de tratar-se de relação de emprego.

A tecnologia, muitas vezes, se insere nos processos produtivos melhorando as condições de vida e de trabalho dos empregados. Mas pode se dar o contrário, com incremento de afazeres, mudança na relação tempo de trabalho (trabalho em tempo integral) ou mesmo redução de postos de trabalho, tornando prescindível o trabalhador no processo produtivo. Constatações que obviamente também podem ser trazidas para o campo da docência.

É o caso de se refletir sobre o sentido a ser dado a tais tecnologias no trabalho docente e à necessidade de uma adequada regulação do uso das tecnologias da informação no trabalho docente a distância. No entanto é um caminho cujo sentido é inequívoco. A título de exemplo, relembre-se a prática jurídica que, com a implementação crescente do processo eletrônico, (Lei 11.419/06, PJe, Resolução n. 185/CNJ), será cada vez mais mediada por meios tecnológicos, a impactar tanto no âmbito docente das disciplinas do eixo prático do curso de Direito, quanto no exercício das atividades cotidianas desses profissionais.

Ocorre que, como já foi dito, num quadro de tendente precarização da atividade docente na $E A D$, em que a lei foi editada com vistas à proteção em face a automação (art. 70, XXVII, CF), deve-se compatibilizar a interpretação normativa com os avanços tecnológicos, a fim de que se acolham as novas formas de se desenvolver o trabalho docente, sem que isso seja causa de violação aos princípios laborais de resguardo do trabalhador, conquistados ao longo dos anos, trazendo assim efetivo proveito social e econômico, sem prejuízo da manutenção e incremento da qualidade da educação. Desse modo, a educação a distância deve encurtar a distância professor/aluno e não massificar o ensino.

Verifica-se que o teletrabalho costuma ser analisado apenas sob uma perspectiva negativa (alienação no processo do trabalho ${ }^{5}$, hiperconexão ao trabalho e, paradoxalmente, isolamento e dificuldade de integração, mitigação da atuação sindical ${ }^{6}$, diminuição da privacidade). Entretanto, os estudos realizados também constatam pontos positivos

$\underline{5}$ Foge aos objetivos deste trabalho a análise dos reflexos do teletrabalho nas avaliações, que tendem a se tornar impessoais e mecanizadas, o que merece, sem dúvida, um estudo mais detalhado.

\footnotetext{
6 Quanto a este aspecto desconfia-se que, ao contrário, as novas tecnologias possam, por outro lado, ser utilizadas como fator de agregação, como, aliás, vem ocorrendo em diversos outros campos da vida social
}

Revista @rquivo Brasileiro de Educação, Belo Horizonte, vol.2, num.3, jan-jun, 2014. 
para os teletrabalhadores. Tremblay chama atenção para o fato de que "apesar de alguns serem monitorados à distância, os teletrabalhadores sentem que dispõem de um grau de liberdade considerável em seu trabalho" (TREMBLAY, 2002, p.60).

Sim, porque a interpretação da norma não deve ser restritiva de tal modo que impeça a utilização dos meios tecnológicos na educação e na atividade docente. Desconfia-se que isso, mesmo se fosse o pretendido, não seria alcançado. Portanto, o que se deve fazer é harmonizar a prática cotidiana do trabalho com as proteções necessárias e razoáveis dos teletrabalhadores, aqui compreendidos os "teledocentes".

Desse modo, preenchidos os pressupostos da relação de emprego - considerando-se que os meios telemáticos e informatizados de comando, controle e supervisão se equiparam, para fins de subordinação jurídica, aos meios pessoais e diretos - vislumbra-se que o teletrabalhador docente poderá fazer jus ao recebimento de hora extra, adicional noturno e até mesmo assistência em caso de acidente de trabalho, entre outros direitos trabalhistas. Claro que há um enorme campo a ser desenvolvido quanto aos parâmetros de verificação de horários, produção, etc., o que já vem ocorrendo.

A pessoalidade - significando que o contrato de trabalho é celebrado em virtude das qualificações pessoais do empregado - fica garantida no teletrabalho por meio de senhas e assinaturas digitais. A própria idéia da subordinação jurídica, não se olvide, deve ser relativizada para a função docente, compatibilizando-a com a liberdade de ensino, princípio albergado no art. 206, II, da Constituição Federal.

$\mathrm{E} O$ art. $6^{\circ}$ da CLT, na nova redação, não abre mão de que se faça presente o poder de direção exercido pelo empregador, mesmo a distância. A subordinação jurídica, portanto, não se restringe ao controle de jornada. Mas, é certo que a forma de controle das horas e o comando, controle e a supervisão ${ }^{7}$ do trabalho, no teletrabalho, estão gerando polêmicas, apesar de esse controle de jornadas e horários poder ser feito utilizando-se as mesmas tecnologias que possibilitam o teletrabalho:

Para que o teletrabalhador venha a pleitear horas extras, essas somente poderão existir, no entendimento de vários autores, quando houver por parte da empregadora o controle da jornada. As empresas têm se utilizado de softwares chamados "time sheets", que não só controlam o início, intervalo e término das jornadas, bem como a produção do trabalho realizado. (GROSSI, 2008, p. 357).

7 Pacificou-se no Tribu-
nal Superior do Traba-
lho, a partir da decisão
no Recurso de Revista n.
61300.23 .2000 .5 .10 .0013 ,
rel. Min. João Oreste Dela-
zen, a orientação segundo
a qual é possível ao em-
pregador monitorar e-mail
corporativo utilizado pelo
empregado, sem violação à
sua privacidade/intimidade,
desde que respeitada a exi-
gência de comunicação pré-
via, restringindo a finalidade
estritamente profissional da
ferramenta.

7 Pacificou-se no Tribunal Superior do Trabalho, a partir da decisão no Recurso de Revista n. 61300.23.2000.5.10.0013 zel. Min. João Oreste Delaa qual é possível ao empregador monitorar e-mail corporativo utilizado pelo empregado, sem violação à sua privacidade/intimidade, desde que respeitada a exigência de comunicação préestritamente profissional da ferramenta. 
Barros afirma que é possível:

[...] aplicar ao teletrabalhador as normas sobre jornada de trabalho, quando estiver em conexão permanente com a empresa que lhe controla a atividade e o tempo de trabalho mediante a utilização de um programa informático, capaz de armazenar na memória a duração real da atividade, dos intervalos, ou o horário definido pela exigência dos clientes do empregador, sem que 0 teletrabalhador tenha liberdade para escolher as horas que pretende trabalhar ao dia. Não há incompatibilidade entre o teletrabalho e a jornada extraordinária e, consequentemente, é possível também fixar o salário por unidade de tempo. (BARROS, 2011, p. 263).

Nesse contexto e sem descurar do princípio da realidade acima destacado, pode-se antever, no trabalho docente, a distância como uma tendência que, ao invés de horários e jornadas rígidas, o controle se dê por metas e tarefas, sendo, necessário, a rigor, se dimensionar de ${ }^{8} \mathrm{~A}$ propósito, $\mathrm{o}$ art. $10 \mathrm{da}$ Resolução do Tribunal Superior do Trabalho somaneira razoável as metas a serem alcançadas ${ }^{8}$, evitando-se excesso bre o teletrabalho no âmde trabalho e indefinição de horários. A apuração tende a se dar por bõe daquela Corte disresultado, com fixação de metas qualitativas e quantitativas a serem metas de desempenho alcançadas, valendo para tal circunstância o cumprimento do horário, sem prejuízo da obrigatoriedade de, por exemplo, manter telefones de pelos servidores em regime de teletrabalho equicontato permanentemente atualizados e consultar diariamente a caixa da respectiva jornada de postal individual de correio eletrônico, oferecer respostas aos alunos num dado tempo, entre outras.

Não obstante, vislumbra-se a possibilidade de utilização de mecanismos também informatizados de controle e fiscalização do exercício da docência no que diz respeito, entre outros aspectos, ao tempo despendido, horários e dias possíveis de acesso, entre outras medidas. A solução prática passa necessariamente pela incidência dos princípios da razoabilidade e proporcionalidade na solução das controvérsias.

Porém, nada impede que o contrato de trabalho preveja que o teletrabalhador, apesar de vinculado a comandos remotos, não estará sujeito ao cumprimento de uma jornada rígida e que o horário observado para ele não será objeto de controle e fiscalização por parte do empregador, caracterizando o trabalho como de natureza externa. $\mathrm{E}$, também, para prever que o teletrabalhador docente tem a obrigação de interromper o seu trabalho, para repousar e alimentar-se durante a jornada, além de preservar, espontaneamente, o intervalo de no mínimo

Revista @rquivo Brasileiro de Educação, Belo Horizonte, vol.2, num.3, jan-jun, 2014. 
A lei n. 12.551/2011 e seus reflexos no teletrabalho docente na educação a distância.

onze horas de repousos entre o início de um expediente de trabalho e outro.

Por outro lado, não se afasta a possibilidade de se passar a contratar o docente enquanto pessoa jurídica para tentar descaracterizar a relação trabalhista, ou então tentar alçá-lo a exercente de cargo de confiança, circunstância última que afastaria o direito a horas extras (art. 62, II, CLT). Ou mesmo de a divisão de horas/jornadas, com vistas à realização das metas, pautar-se em superdimensionamento do tempo do docente, com disposição expressa da necessidade de autorização do empregador para a realização de horas extras ou noturnas. A divergência nos tribunais quanto ao pagamento de horas extras no teletrabalho docente não será pequena.

Os abusos deverão ser objeto de apuração por via própria. 0 que se defende é que a dificuldade de se dimensionar as questões das atribuições, das jornadas e horas de trabalho - no trabalho a distância e no teletrabalho docente em especial - não seja por si só um fator impeditivo do desenvolvimento dessa nova vertente da atividade docente. O empregador, mesmo a distância, pode controlar e fiscalizar a qualidade e a quantidade do serviço executado. A subordinação existirá no que tange esses aspectos e não ao horário da jornada. (GROSSI, 2008).

Não se questiona que em linha de princípio seja do empregador (instituição de ensino) a responsabilidade pela disponibilização de equipamentos para o desempenho do teletrabalho, em sua grande maioria, no ambiente da Internet, ao menos como forma de compensar a redução dos custos de manutenção da infraestrutura física, que fica dispensada. As empresas já vêm disponibilizando celulares/smartphones, bips, pagers, e-mail, tablets, telefone corporativo e também os sistemas informáticos como o Skype, programas de mensagens instantâneas como o MSN, e até mesmo as redes de relacionamento, como Facebook, para "controle e supervisão". O mesmo deve ocorrer com as instituições de ensino. $O$ dispositivo legal do parágrafo único do art. $6^{\circ}$ da CLT não foi suficientemente claro, mas, nem por isso, se questiona que todos esses recursos podem ser utilizados para configurar a subordinação jurídica caracterizadora da relação de emprego e geradora dos direitos trabalhistas inerentes.

Claro que, no dia a dia muitas dificuldades poderão surgir, como, por exemplo, a questão da responsabilidade pela resolução de problemas ligados à quebra dos equipamentos, deslocamentos até a sede da

Revista @rquivo Brasileiro de Educação, Belo Horizonte, vol.2, num.3, jan-jun, 2014. 
instituição, limites e utilização indevida dos equipamentos fornecidos, uso ergonômico do equipamento, regras a serem observadas na hipótese de eventuais afastamentos ou interrupções do trabalho, ocasionados por problemas técnicos com equipamentos ou dados utilizados, dentre outras. São questões que já eram levados à Justiça do Trabalho e que não se alteraram com a Lei n. 12.551/20119.

A principal delas seria uma maior restrição à intimidade e à vida privada do teletrabalhador, considerando-se que, na maioria das vezes, o teletrabalhador docente franqueia sua própria casa à relação de trabalho. Afinal, como ficaria o direito à inviolabilidade do domicílio frente a "vistorias" impostas pelo empregador? Mas, e se o domicílio do teletrabalhador é inviolável quem será responsável pela manutenção de padrões de higiene, segurança e de ergonomia no local ou locais de prestação de serviços?

O que a Lei n. 12.551/2011 quis diminuir foi a insegurança quanto ao enquadramento do teletrabalhador como empregado. Insegurança essa que levava ao aumento de conflitos trabalhistas e até mesmo a uma redução do ritmo das alterações oriundas do teletrabalho, o que não é desejável. Ao fazê-lo, manteve o paralelo entre o teletrabalho e o trabalho em domicílio (arts. $6^{\circ}$ e 83 da CLT). Mas, a premissa maior que parece ter orientado a alteração legislativa parece ser mesmo a da igualdade de tratamento entre os trabalhadores a distância e os demais trabalhadores, paralelo que deve ser transposto para o docente da educação a distância.

Para muitas empresas, bastará regular a disponibilização e o uso dos equipamentos aos trabalhadores, para que os utilizem estritamente em horário normal de trabalho e desde que autorizado, para uso exclusivo. A solução é simplista e não resolve a problemática inerente ao teletrabalho docente, no qual a flexibilização do horário parece andar colada. Até porque, se assim fosse, haveria para o empregador apenas a redução do gasto com infraestrutura dos locais de trabalho e, para o trabalhador, a redução do tempo de deslocamento, aspectos importantes, mas que não esgotam as questões ligadas a essa prática profissional.

Na hipótese do teletrabalho docente - espécie bastante singular de prestação de serviços - a questão se altera um pouco, na medida em que a própria normatização da educação a distância impõe a realização de atividades assíncronas. $O$ grande diferencial da educação a distância

Revista @rquivo Brasileiro de Educação, Belo Horizonte, vol.2, num.3, jan-jun, 2014. 
parece ser mesmo essa possibilidade de se estudar em qualquer momento, sempre com a orientação de um teledocente.

De todo modo, entende-se que a saída hermenêutica proposta, baseada no art. $6^{\circ}$ da CLT na redação atual, seja mais conveniente do que aquela constante do Projeto de Lei 4505/2008, que a pretexto de regulamentar o trabalho a distância, acabava por dispor em seu art. 6º, parágrafo único, que: "Em razão do caráter de controle de jornada aberta e, via de regra, de forma virtual, aos empregados teletrabalhadores não será contemplado o direito às horas extras, devendo a remuneração ajustar-se às horas normais de trabalho", dispositivo supostamente amparado no art. 62, I, da CLT, mas de duvidosa constitucionalidade frente ao art. 70, XIII, da Constituição Federal.

Por outro lado, deve-se entender que, a rigor, o teletrabalhador docente não permanece de sobreaviso (art. $4^{\circ}$ e $244, \S 1^{\circ}$, da CLT) simplesmente por desempenhar seu trabalho à distância e mediado por meios informatizados. A subordinação jurídica prevista na nova redação do art. $6^{\circ}$ da CLT não se confunde com controle de jornada, nem com fiscalização de cumprimento de jornada. O sobreaviso, para gerar o pagamento de horas extraordinárias, requer restrição à liberdade de locomoção do empregado, quando no teletrabalho o que ocorre é justamente o contrário. Situações diversas devem merecer apreciação da Justiça do Trabalho ${ }^{10}$, mas claro que o teletrabalhador docente pode também fazer jus às horas de sobreaviso quando, por exemplo, permanecer de plantão, dada alguma atividade avaliativa ou mesmo por exigência de algum experimento científico.

Um último ponto refere-se à possibilidade de um docente, no exterior, para curso de aperfeiçoamento, continuar suas atividades por meio dos recursos fornecidos pela educação a distância. Nesse caso, tendo a contratação ocorrida no Brasil, aplica-se a legislação brasileira naquilo que se mostrar mais favorável do que a legislação do local em que o teletrabalhador estiver desempenhando suas atividades.

\section{Considerações Finais}

A Lei n. 12.551/2011 alterou o art. $6^{\circ}$ da CLT para explicitar em seu parágrafo único que "Os meios telemáticos e informatizados de comando, controle e supervisão se equiparam, para fins de subordinação jurídica, aos meios pessoais e diretos de comando, controle e supervisão

10 A propósito a redação atual da Súmula n. 428 do TST: "SOBREAVISO. APLICAÇÃO ANALÓGICA DO ART. 244, § 2。 DA CLT. I - O uso de instrumentos telemáticos ou informatizados fornecidos pela empresa ao empregado, por si só, não caracteriza o regime de sobreaviso. II - Considera-se em sobreaviso o empregado que, à distância e submetido a controle patronal por instrumentos telemáticos ou informatizados, permanecer em regime de plantão ou equivalente, aguardando a qualquer momento o chamado para o serviço durante o período de descanso."

Revista @rquivo Brasileiro de Educação, Belo Horizonte, vol.2, num.3, jan-jun, 2014. 
do trabalho alheio".

A referida legislação destina-se também aos teledocentes, assim entendidos os teletrabalhadores da docência, que desempenham suas funções na educação a distância.

Apesar de alguns questionamentos principalmente no que diz respeito a horas extras, a referida norma não deve servir de desestímulo ao oferecimento de educação a distância pelas instituições de ensino, mesmo porque, pouco inovou na matéria, apenas explicitando os pressupostos caracterizadores na relação de emprego, mais especificamente a telessubordinação, isto é, o teletrabalho é compatível com a subordinação trabalhista.

A depender dos desdobramentos práticos e da condução das controvérsias pela Justiça do Trabalho, pode haver alguma alteração no modo de se controlar o trabalho realizado pelo teletrabalhador docente na educação a distância, com divisão do trabalho por tarefas e metas a serem cumpridas, a partir de uma divisão razoável e proporcional do tempo de trabalho, sujeita a controles também dos meios informatizados. Controles esses que tendem a serem cada vez mais avançados.

Do ponto de vista do docente da educação a distância, a legislação vem explicitar que "caracterizados os pressupostos da relação de emprego" não haverá diferença entre ele e o docente da educação presencial, sendo que "os meios telemáticos e informatizados de comando, controle e supervisão se equiparam, para fins de subordinação jurídica, aos meios pessoais e diretos de comando, controle e supervisão do trabalho alheio".

A docência a distância, ou teledocência, não representa, necessariamente, uma piora nas condições de prestação do trabalho docente.

A questão remanesce então, no que diz respeito aos direitos trabalhistas, quanto ao dimensionamento do trabalho docente, que deve pautar-se em critérios razoáveis, de modo a compatibilizar-se a interpretação normativa com os avanços tecnológicos, a fim de que se acolham as novas formas de se desenvolver o trabalho docente sem que isso seja causa de violação aos princípios laborais de resguardo do trabalhador, conquistados ao longo dos anos, trazendo, assim, efetivo proveito social e econômico, sem prejuízo da manutenção e incremento da qualidade da educação.

Assim, a interpretação da norma não deve ser restritiva de tal

Revista @rquivo Brasileiro de Educação, Belo Horizonte, vol.2, num.3, jan-jun, 2014. 
A lei n. 12.551/2011 e seus reflexos no teletrabalho docente na educação a distância.

modo que impeça a utilização dos meios tecnológicos na educação e na atividade docente. Mas, igualmente, não deve servir de pretexto para uma maior precarização do trabalho docente, quadro já constatado na educação a distância.

A dificuldade de se dimensionar a questão das jornadas e horas de trabalho no teletrabalho docente não deve ser erigida como fator impeditivo do desenvolvimento dessa nova vertente de atividade. E, nesse contexto, o advento da Lei $12.551 / 2011$ pode servir de mola propulsora para um novo momento da teledocência.

O teletrabalho e mesmo a educação a distância, ou a semipresencial, parecem caminhos sem volta, no atual estágio de desenvolvimento tecnológico e social. Exemplos dessa nova fase são as recentes Portarias n. 139/2009 e 99/2010, do Tribunal de Contas da União, e Resolução

${ }^{11} \mathrm{O}$ TST expandiu a utilização do teletrabalho Administrativa n. 1.499, do Tribunal Superior do Trabalho (TST), de 01.02.2012 ${ }^{12}$, que disciplinam, para os seus servidores, o teletrabalho. entre seus servidores por meio do ATO CDEP.SEGPES.GDGSET.GP No

Presume-se que a regulamentação do teletrabalho pelo TST deva influir na maneira como a Justiça do Trabalho irá abordar o tema, o 327, DE 16 DE JUNHO DE 2014. que não afasta a necessidade de em cada caso a questão também vir disciplinada no contrato de trabalho firmado entre instituição de ensino e teletrabalhador docente.

\section{REFERÊNCIAS}

BARROS, Alice Monteiro de. Curso de Direito do Trabalho. 7. ed. São Paulo: LTr, 2011.

BELLONI, Maria Luiza. Educação a distância. Campinas: Autores Associados, 2003. 115p.

BRASIL. Lei n 9.394, de 20 dez. 1996. Lei de Diretrizes e Bases da Educação Nacional. Diário Oficial, Brasília, 23 dez. 1996. Disponível em: < http:// www.planalto.gov.br/>. Acesso em: 27 fev. 2014.

BRASIL. Lei no 12.551, de 15 dez. 2011. Altera o artigo $6^{\circ}$ da Consolidação das Leis do Trabalho e dá outras providências. Diário Oficial, Brasília, 16 dezembro. 2011. Disponível em: http://www.planalto.gov.br. Acesso em: 27 fev. 2014.

BRASIL. Ministério da Educação. Secretaria de Educação a Distância. Referenciais de qualidade para educação superior a distância. Brasília, agosto de 2007, 31p. Disponível em: < http://portal.mec.gov.br/seed/ 
arquivos/pdf/legislação/refead1.pdf>. Acesso em: 27 fev. 2014.

BRASIL. Constituição. Constituição da República Federativa do Brasil. Disponível em: <http://www.planalto.gov.br >. Acesso em: 27 fev. 2014.

BRASIL. Tribunal Regional do Trabalho da $3^{a}$ Região (Minas Gerais). Recurso Ordinário TRT/00423-2009-042-03-00-1 RO. Disponível em: <http://www.trt3.jus.br>. Acesso em: 27 fev. 2014.

BRASIL. Tribunal Superior do Trabalho. Recurso de Revista n. 61300.23.2000.5.10.0013. Disponível em: < http://www.tst.jus.br $>$. Acesso em: 27 fev. 2014.

BRASIL. Tribunal Superior do Trabalho. Resolução Administrativa n. 1.499. Disponível em: <http://www.tst.jus.br>. Acesso em: 27 fev. 2014.

CAPELARI, Luciana Santos Trindade. Teletrabalho: alternativa para o trabalhador num mundo globalizado e flexibilizado. In: CASTRO, João Antônio Lima; FERREIRA, Juliana Maria Matos (Coord.). Direito processual e o constitucionalismo democrático brasileiro. Belo Horizonte: PUC Minas, IEC, 2009, p. 937-950.

ESTRADA, Manuel Martín Piño. Panorama Juslaboral do Teletrabalho na América Latina e na Europa. Revista de Direito das Novas Tecnologias. São Paulo: Editora IOB, 2008, v.I.

ESTRADA, Manuel Martín Pino. Os mundos virtuais e o teletrabalho nos tribunais brasileiros: os casos do STF e do TRT de Minas Gerais. Revista do Direito Trabalhista, v. 16, n. 5, p. 11, maio, 2010.

GROSSI, Danilo José. A nova realidade trabalhista teletrabalhadores e home Office. In: CASTRO, João Antônio Lima; NEVES, Isabela Dias (Coord.). Direito processual: uma análise crítica no Estado democrático de direito. Belo Horizonte: PUC Minas, IEC, 2008, p. 351-363.

MEZZAROBA, Orides; MONTEIRO, Cláudia Servilha. Manual de metodologia da pesquisa no direito. $3^{a}$ ed. rev. São Paulo: Saraiva, 2006, 344p.

NASCIMENTO, Amauri Mascaro. Curso de direito do trabalho: história e teoria geral do direito do trabalho: relações individuais e coletivas do trabalho. $23^{a}$ ed. rev. e atual. São Paulo: Saraiva, 2008, 1312p.

OLIVEIRA, Maria Auxiliadora; PASCHOALINO, Jussara B.; MATIAS, Virgínia Queiroz. O trabalho do professor do ensino superior no contexto da pós-modernidade. IN: Seminário de La Red de Studios sobre Trabajo Docente: nuevas regulaciones em América Latina, 7, Buenos Aires, p. 2035, 3-5 jul./2008. 
A lei n. 12.551/2011 e seus reflexos no teletrabalho docente na educação a distância.

TREMBLAY, Diane-Gabrielle. Organização e satisfação no contexto do teletrabalho. Rev. adm. empres. [online]. 2002, vol.42, n.3, pp. 54-65. Acesso em: 27 fev. 2014. 